http://jmscr.igmpublication.org/home/

ISSN (e)-2347-176x ISSN (p) 2455-0450

crossref DOI: https://dx.doi.org/10.18535/jmscr/v7i10.160

Journal Of Medical Science And Clinical Research

IGM Publication

An Official Publication of IGM Publication

\title{
Incomplete Pentalogy of Cantrell with Craniorachischisis - A Rare Case Report
}

\author{
Authors \\ Dr Anjali Saji ${ }^{*}$, Dr Aparna B Raj ${ }^{1}$, Dr Nithya B G ${ }^{1}$, Dr Nishitha T $^{\mathbf{2}}$ \\ ${ }^{1}$ Junior Resident, Dept of Pediatrics, M.K.C.G Medical college, Berhampur, Ganjam, Odisha,760004, India \\ ${ }^{2}$ Junior Resident, Dept of Obstetrics \$ Gynaecology, M.K.C.G Medical college, Berhampur, Ganjam, \\ Odisha, 760004, India \\ *Corresponding Author \\ Dr Anjali Saji \\ Address: PG Ladies Hostel, M.K.C.G Medical College, Berhampur, Odisha, 760004, India
}

\begin{abstract}
Cantrell's Pentalogy is a rare congenital malformation consisting of supraumbilical abdominal defect, defect in lower part of sternum, agenesis of anterior portion of diaphragm, ectopiscordis and an intra cardiac defect. Hereby, we are reporting a case of Incomplete Pentalogy of Cantrell with, ectopiacordis, with absent pericardium, gastroschisis and Craniorachischisis.

Keywords: Pentalogy, Cantrell, ectopiacordis, Craniorachischisis.
\end{abstract}

\section{Introduction}

Pentalogy of Cantrell is a rare congenital syndrome that occurs sporadically with variable degrees of expression. It includes a lower sternal defect, midline supraumbilical thoracoabdominal defect, defect in anterior diaphragm, ectopiacordis and intra cardiac defects. The disease is extremely rare and lethal when in full expression and hence it necessitates prenatal diagnosis by anomaly scan. Here we report a case of Incomplete Pentalogy of Cantrell with craniorachischisis due to its rarity.

\section{Case Report}

A female neonate was admitted to SNCU, MKCG Medical College, after 20 minutes of delivery for major congenital malformations. She was born to a 30 year old P4L3 mother, who was an unbooked and unimmunized case, at 34 weeks of gestation, with a birth weight of $1.6 \mathrm{~kg}$, with no significant antenatal history suggestive of any teratogenic exposure, through spontaneous labour vaginally. Her past history revealed 1 still birth, and the USG done at labour room revealed Gastroschisis and polyhydramnios. APGAR score was 1 at $1 \mathrm{~min}$ and 3 at $5 \mathrm{~min}$. Baby was immediately transferred to SNCU, and was found to have a defect in thoracoabdominal wall, ectopiacordis with pulsations, absence of pericardium, evisceration of intestines and craniorachischisis and bilateral club foot. (Fig 1,2). The facial structues were dysmorphic with presence of cleft palate. Spleen, large intestine, small intestine and enlarged liver were identified in the gastroschisis. The patient succumbed after 1.5 hours of delivery. 


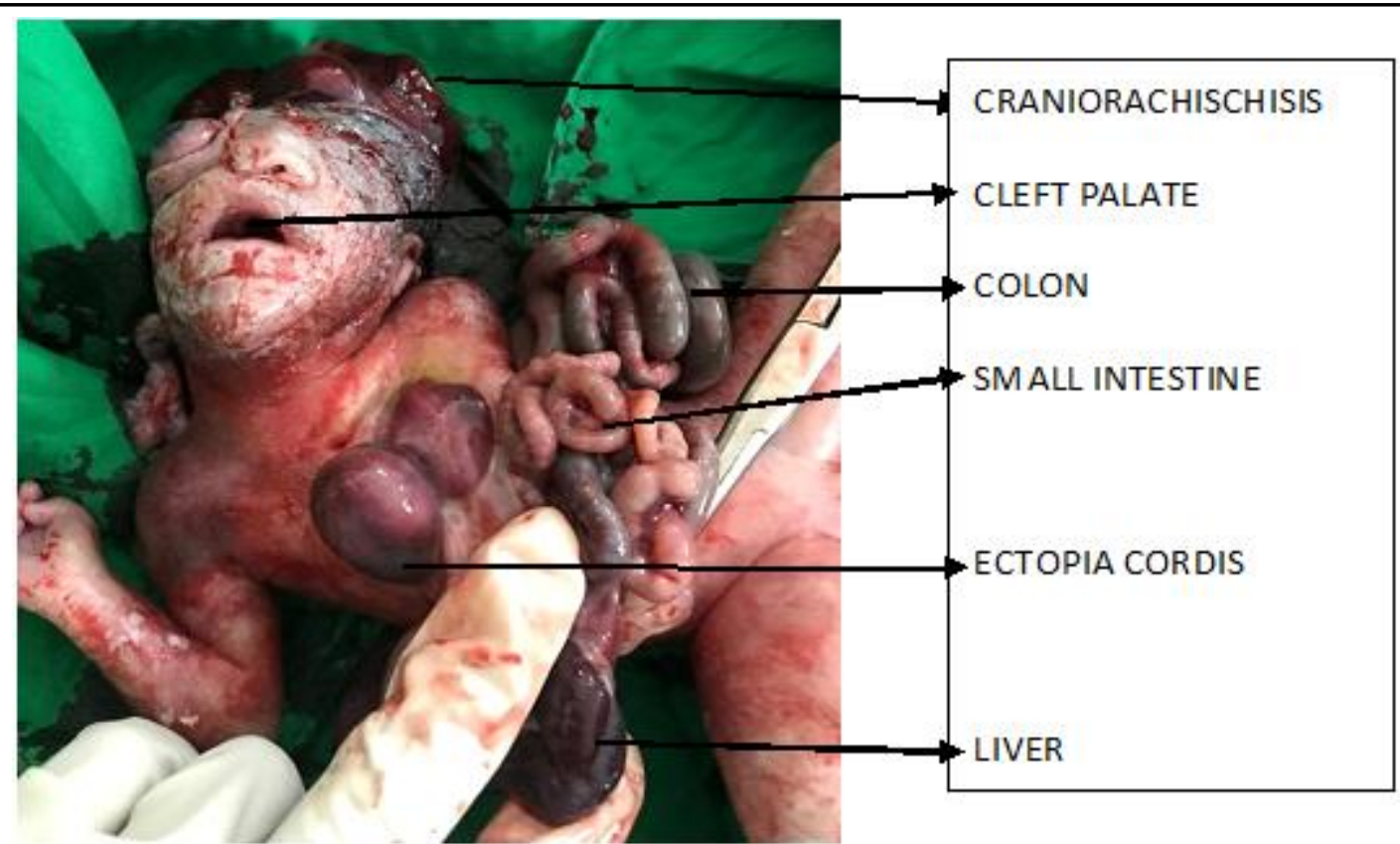

Figure 1: The baby born at 34 weeks of gestation with Incomplete Pentalogy of Cantrell having lower sternal defect with ectopiacordis, entire liver, spleen and gastroschisis with intestinal loops, Craniorachischisis and clubfoot. cleft palate also noted.

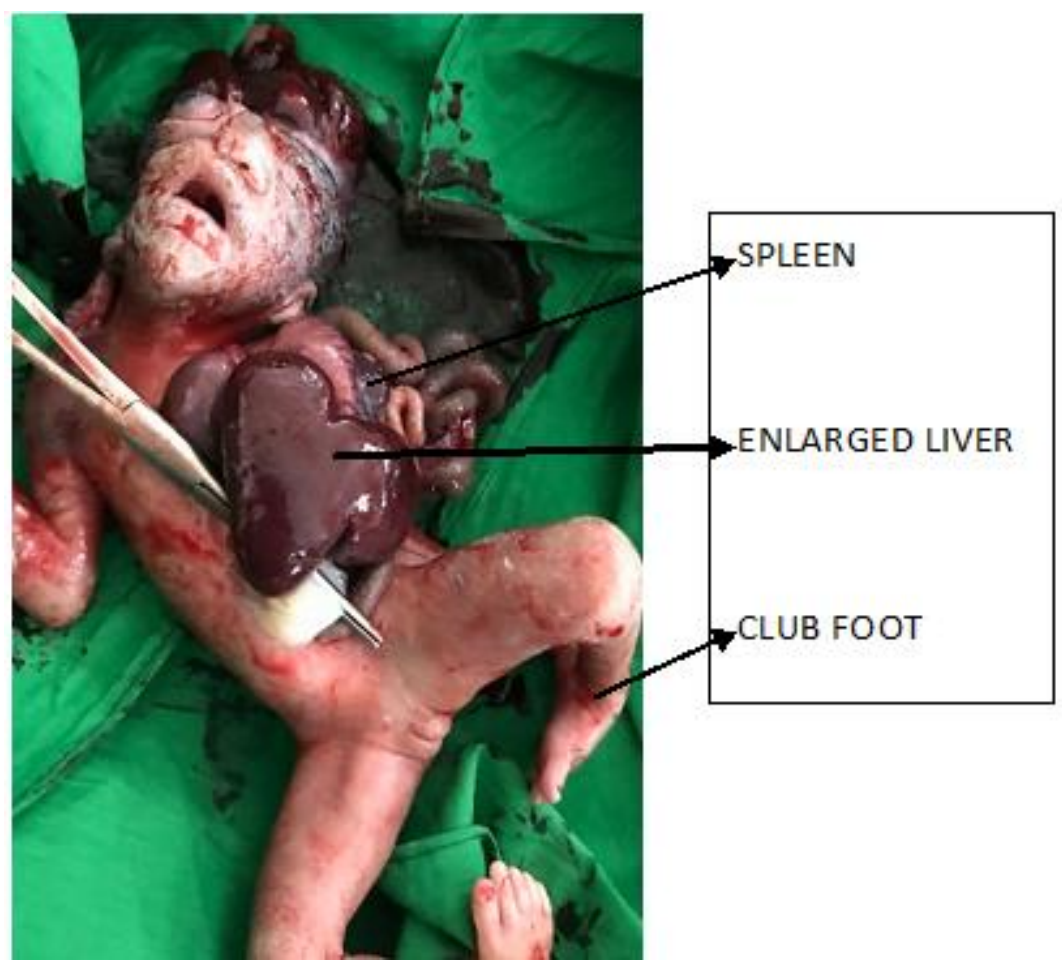

Figure 2: Baby born at 34 weeks of gestation with Incomplete Pentalogy of Cantrell showing Gastroschisis with enlarged liver and clubfoot. Cleft palate is also noted.

\section{Discussion}

First described by Cantrell et al in $1958^{(1)}$; Pentalogy of Cantrell is characterized by

1. Ectopia Cordis

2. Midline supraumbilical abdominal defect

3. Lower sternal defect
4. Anterior diaphragmatic defect

5. Intracardiac defect

Because not every case may have all the findings, Tayoma $^{(2)}$ suggested a classification scheme

i. Certain diagnosis: All 5 defects are present. 
ii. Probable diagnosis: 4 defects present including intracardiac and anterior abdominal wall defects.

iii. Incomplete expression: Various combination of defects and includes a sternal abnormality.

The prevalence of Pentalogy of Cantrell is about 1 in 65000 live births and is classified as a developmental defect of midline anterior abdominal wall. Full syndrome is very rare and severe, but incomplete forms is combination of two or three defects were reported frequently ${ }^{(3)}$. Intracardiac anomalies reported are VSD (100\%), ASD (52\%), Pulmonary stenosis (33\%), and TOF $(20 \%)^{(2)}$

Because of various defects, the condition is said to be multifactorial in origin, including teratogen, gene mutation, chromosomal anomalies like Trisomy 13, 18 and disrupted vessels defect ${ }^{(4)}$. The widely accepted hypothesis is failure in migration of primary mesodermic structures of chest and abdomen during gestational age of 1418 days. Craniorachischisis is due to complete failure of neurulation and characterized by anencephaly/exencephaly continuing with open spine (spinal dysraphism)

Our patient had 3 of the defects and craniorachischisis. Intra cardiac defects and other visceral anomalies couldn't be identified since the baby expired in 1.5 hours of delivery, giving no time for further treatment and parents dissented for autopsy.

Carmi et al reported some cases with encephalocele and cleft lip in association with abdominal wall defects and as Pentalogy Of Cantrell $^{(5)}$, only limited reports. Similar cases were reported by Polat et $\mathrm{al}^{(6)}$ and Doganay $\mathrm{S}$ et $\mathrm{al}^{(7)} \mathrm{As}$ far as we know, this is the first report of Pentology Of Cantrell and craniorachischisis, reported from Eastern India.

Antenatal USG could have identified this defects after 12th week of gestation as fetal abdominal wall defect orectopiacordis, which further signifies the importance of anomaly scans.
Prognosis and survival depends on extent of ventral wall, sternal and cardiac defects. When there is association of central nervous system the prognosis becomes even poorer. Mean survival rate without any interventional surgery is 36 hours. $^{(8)}$

\section{Conclusion}

Pentalogy of Cantrell is a very rare and serious condition, with poor survival rates, yet prenatal diagnosis is possible and early counselling should be made, and families should be informed about prognosis with a dignified team involving Obstetricians, Neonatologist, Paediatric Cardiologist, Paediatric surgeons, Geneticist and an option for MTP to be made available to parents.

\section{Bibliography}

1. Cantrell JR, Haller JA, Ravitch MM.A syndrome of congenital defects involving the abdominal wall, sternum, diaphragm, pericardium and heart. Surg Gynecol Obstet .1958;107(5):602-14.

2. Toyama WM. Combined congenital defects of the anterior abdominal wall, sternum, diaphragm, pericardium and heart: a case report and review of the syndrome .pediatrics.1972;50;778-792.

3. Van Allen MI et al .Limb -body wall complex : limb and spine defects . Am J Med Genet .1987:28(3):549-65.

4. Chen CP. Syndromes and disorders associated with Omphalocoele (11): OEIS complex and Pentology of Cantrell .taiwan J Obstet .2007;46(2): 103-10.

5. Carmi R,et al : Pentology of Cantrell and associated midline anomalies : a possible ventral midline development field: Am J Med Genet 1992;42(1):90-95.

6. Polat I, Gul A, Aslan H, Cebeci A, Ozseker B, Caglar B ,et al.Prenatal diagnosis of pentalogy of Cantrell in three cases, two with craniorachischisis. J Clin Ultrasound.2005;33:308-311 
7. Doganay S, Kantarci M, Tanriverdi EC. Pentalogy of Cantrell with Craniorachischisis: MRI and ultrasonography findings. Ultraschall Med.2008;29:278-280.

8. Forzano F, Danbency PE, et al .Midline Raphe, sterna cleft and other midline anomalies: a new dominant syndrome ?Am J Med gent A.2005:135(1):9-12. 